\title{
Emergency medicine in Jamaica
}

\author{
Archibald McDonald, FACS, DM(Surg); ${ }^{*}$ Jean Williams-Johnson, DM(Emerg Med $){ }^{\dagger}$ \\ Eric Williams, DM(Emerg Med $){ }^{\dagger}$ Simone French, DM(Emerg Med $)^{\dagger}$
}

\section{Introduction}

Jamaica is the 4th-largest Caribbean island, with an area of $10991 \mathrm{sq} \mathrm{km} \mathrm{(4244} \mathrm{sq} \mathrm{miles)} \mathrm{and} \mathrm{a} \mathrm{population} \mathrm{of} 2.65$ million. ${ }^{1}$ The island is situated approximately $966 \mathrm{~km}$ (600 miles) south of Miami, Florida. Jamaica is divided into 14 parishes, with the capital city of Kingston located in the southeast region. Approximately one-half of the population lives in the metropolitan region of Kingston and its environs. The island obtained its independence from Britain in 1962 and since then has functioned as a constitutional parliamentary democracy. The country is heavily dependent on tourism to sustain its economy.

Following 4 years of contraction between 1996 and 1999, the Jamaican economy grew during 2000-2003. The gross national product was approximately $\$ 0.11$ billion (USD) in 1999. ${ }^{2,3}$ More than $50 \%$ of the national budget is used to service debts and consequently only about $7 \%$ goes to health care, compared with $14.8 \%$ for the Bahamas and 15\%-16\% for Barbados., ${ }^{2,4}$ Although all patients seeking health care at public institutions are required to pay a small percentage of the cost of their care, no one is denied access. Private care is widely available but is affordable to only a small proportion of the population.

\section{Health care}

The 23 public hospitals on the island provide approximately $80 \%$ of tertiary health care ${ }^{2,4}$ and most of the emergency care. Two major adult hospitals and a pediatric hospital provide 24-hour emergency services for Kingston and its environs. These are the Kingston Re- gional Hospital, the University Hospital of the West Indies (UHWI) and the Bustamante Children's Hospital. The UHWI is the main teaching hospital on the island and is attached to the University of the West Indies, which is a regional Caribbean institution. It is a well equipped 500-bed facility with all the major disciplines and investigative tools available. The Kingston Regional Hospital and the UHWI are the main adult referral hospitals on the island.

\section{Emergency care}

Emergency medicine (EM) in Jamaica has evolved over the past 14 years, although progress has been hampered by the island's economic difficulties. Prior to 1988 all Jamaican hospitals operated old fashioned "Casualty Departments" staffed by very junior doctors and nurses with no training in EM. ${ }^{5}$ Pre-hospital care was nonexistent, and cases were brought to hospitals usually in private cars or police vehicles. These Casualty Departments provided care for emergency cases and also a significant number of non-

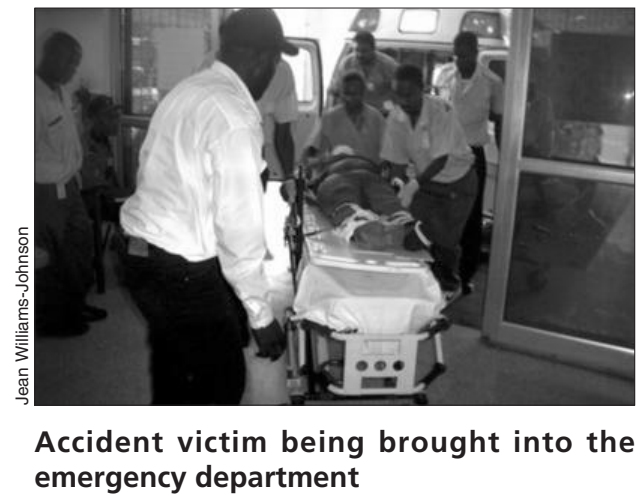

From the *Department of Surgery, and the tDivision of Emergency Medicine, Department of Surgery, Radiology Anaesthesia and Intensive Care, University of the West Indies, Mona, Kingston 7, Jamaica

Received: June 6, 2005; accepted: July 6, 2005

Can J Emerg Med 2005;7(5):340-3 
urgent problems. Without a triage system, emergency cases frequently got lost in the crowd and waited long hours, sometimes with disastrous results.

In 1988, the UHWI established the first emergency department on the island in an attempt to improve the care of emergency and trauma cases. The old "Casualty Department" was divided into the "Accident and Emergency" (A\&E) unit to care for trauma and emergency cases and an ambulatory care unit to provide care for nonurgent cases. Previously there was no senior doctor in charge of the Casualty Department and it was not affiliated with any other department. The new A\&E was administered by the Department of Surgery and a consultant surgeon with an interest in trauma and emergency care supervised a team of junior doctors. Formal in-service training for doctors and nurses was started, undergraduate teaching re-established and research in trauma and EM commenced. This resulted in improved care and stimulated interest nationally in trauma care and EM. Subsequently, all government and private hospitals have renamed their Casualty Departments as A\&E Departments and have upgraded staff as well as equipment. In 1993, the A\&E at the UHWI moved into a new, fully equipped emergency facility.

Today, EM in Jamaica has moved from the "underdeveloped phase" described by Berk. ${ }^{5}$ to the "developing phase" based on the Anglo-American model. ${ }^{5,6}$ The specialty has now gained acceptance by other clinicians, formal training of emergency physicians and emergency nurses has begun,

Table 1. Emergency department case-mix at the University Hospital of the West Indies

\begin{tabular}{lcc} 
Illness & $\begin{array}{c}\text { No. of cases } \\
\text { (and \%) }\end{array}$ & $\begin{array}{c}\text { Mean age, } \\
\text { yr; } \pm \text { SD }\end{array}$ \\
\hline $\begin{array}{l}\text { Injuries and poisoning } \\
\text { Diseases of the respiratory } \\
\quad \text { system }\end{array}$ & $1478(31.0)$ & $28.8 \pm 17.5$ \\
$\begin{array}{l}\text { Diseases of the digestive } \\
\quad \text { system }\end{array}$ & $498(10.5)$ & $35.7 \pm 23.0$ \\
$\begin{array}{l}\text { Diseases of the circulatory } \\
\quad \text { system }\end{array}$ & $275(5.8)$ & $57.4 \pm 20.8$ \\
$\begin{array}{l}\text { Diseases of the genitourinary } \\
\text { system }\end{array}$ & $275(5.8)$ & $37.0 \pm 21.0$ \\
$\begin{array}{l}\text { Psychiatric disorders } \\
\text { Obstetric complications }\end{array}$ & $194(4.1)$ & $30.8 \pm 14.2$ \\
Hematological diseases & $182(3.8)$ & $26.6 \pm 6.6$ \\
CNS conditions & $144(3.0)$ & $25.6 \pm 12.2$ \\
Infectious diseases & $95(2.0)$ & $25.3 \pm 19.4$ \\
Neoplasms & $80(1.7)$ & $31.3 \pm 25.0$ \\
Others & $53(1.1)$ & $46.7 \pm 22.2$ \\
\hline
\end{tabular}

research in the specialty is taking place, and pre-hospital care is being enhanced. Thirteen fully trained emergency physicians have graduated from the Jamaica postgraduate program to date, and there are 23 residents in training. Five of the graduates are full-time consultants at the UHWI, 5 are working in public hospitals across the island, 2 are in the Cayman Islands and 1 is in the Bahamas. Patient volume at the new A\&E at the UHWI has increased from 8000 in 1993 to approximately 48000 in 2004. Injury is the most common presenting problem at both the Kingston Regional Hospital and the UHWI. Forty percent are victims of interpersonal violence. ${ }^{7.8}$ The homicide rate in 2004 was 57 per 100000 population, among the highest in the world. The motor vehicle accident fatality rate of 16 per 100000 is similar to that of the United States but with far fewer vehicle miles travelled each year. ${ }^{9}$ The emergency department case mix is otherwise similar to that seen in the developed world, with an increasing number of visits for chronic diseases such as diabetes and hypertension (Table 1).

\section{Training}

In 1995 a training course for nurses in EM was established, and to date 77 nurses have been trained. A 4-year EM residency program started in 1997. Training is done in conjunction with the emergency department at the Queen Elizabeth Hospital in Barbados, which is also affiliated with the University of the West Indies. Formal training in Trinidad started in January 2005. Training assistance has been provided by a number of emergency departments from North America and England, including Jackson Memorial Hospital in Miami, Florida, St. Mary's Hospital in London, England, Hartford Hospital in Connecticut and the University of Toronto, Toronto, Ont.

The Advanced Cardiac Life Support (ACLS) course was offered for the first time on the island in April 1998, and all 30 participants were successful. This was made possible

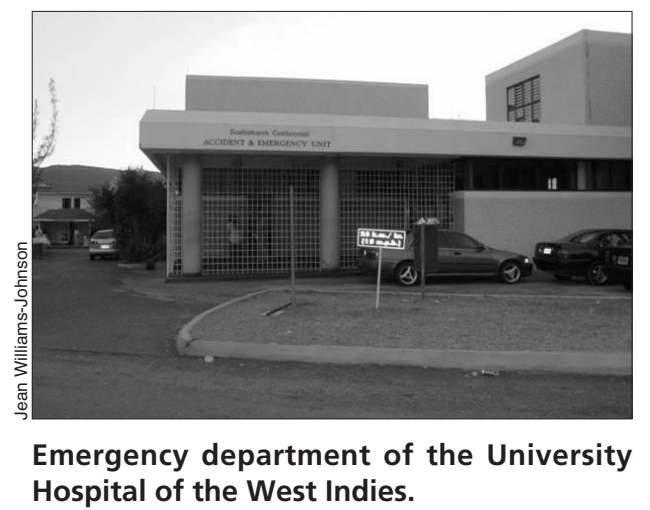


through the visit of a team of qualified ACLS instructors from Howard University. Since then several ACLS courses are run annually by the Heart Foundation of Jamaica and the Jamaican Ministry of Health. The Advanced Trauma Life Support (ATLS) course was held for the first time in Jamaica in May 2001. ${ }^{9}$ This was made possible through assistance from the ATLS faculty in Trinidad and Tobago. The ATLS faculty in Jamaica now conducts 3 courses annually under the auspices of the Jamaican chapter of the American College of Surgeons.

\section{Disaster preparedness}

Jamaica is a disaster-prone country, with hurricanes, earthquakes, floods, fires and transportation accidents. Our worst earthquakes occurred in 1692, when the vibrant buccaneering town of Port Royal liquefied and sank, and in 1907 when most of Kingston was destroyed by fires following a massive earthquake.

Hurricane season in Jamaica begins on June 1st and ends on Nov. 30th. In 1902, 1903, 1944, 1951, 1988 and 2004, major hurricanes made landfall or passed very close to the coast, with disastrous consequences. On several other occasions, near misses caused flooding or wind damage. Hurricane Gilbert, one of our most devastating experiences, hit the island on Sept. 12, 1988, traversing the length of the island in its 8-hour rampage. Although only 45 lives were lost, Gilbert caused $\$ 4$ billion (USD) in damages and crippled the Jamaican economy. Forty percent of the losses were in the agricultural sector, but there was extensive damage to health care facilities, with 2 hospitals completely destroyed and 11 others extensively damaged. Many health centres were damaged, generating additional repair costs of approximately US $\$ 13$ million. Failure of power generation and distribution systems and domestic water facilities left many communities

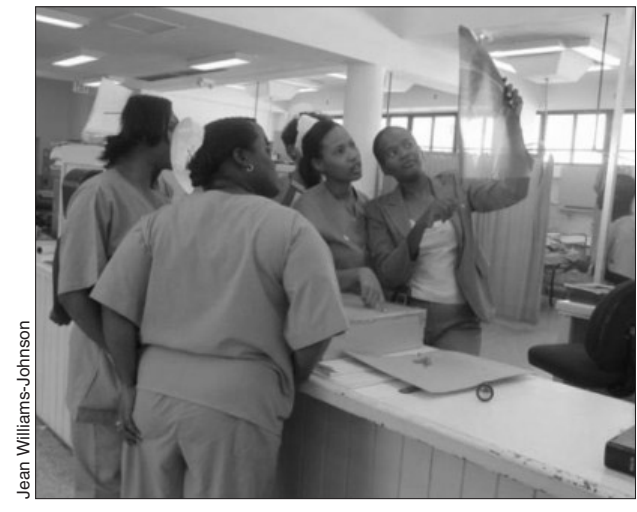

Emergency staff at University Hospital of the West Indies examining an x-ray. without light and water for as long as 3 months. Damage to roads and communication systems resulted in many areas being isolated for many days before help could reach them.

Jamaica ultimately recovered with the help of substantial international assistance, but Hurricane Gilbert taught us many lessons. The most important of these was that a system that cannot cope under normal circumstances will not function adequately in a disaster. Since then, preparations for the next inevitable disaster have increased. Jamaica now has a National Disaster Plan and a National Disaster Health Plan, which were tested on Sept. 14, 2004, during Hurricane Ivan, a Category 5 hurricane that passed within a few miles of the coast. Damage and loss of life were not as severe as with Hurricane Gilbert because of infrastructure improvements and better preparedness.

Disaster response is managed by the National Disaster Committee, which is chaired by the Prime Minister and includes representatives from government ministries, police, fire and voluntary organizations such as the Red Cross and the Council of Churches. The main agency for disaster planning and management is the Office of Disaster Preparedness and Emergency Management (ODPEM). Its main functions are to create and maintain contingency plans at the national, parish and community levels; to promote public awareness of disaster threats and appropriate response; to monitor the effectiveness of hazard mitigation strategies, an integral part of physical and economic planning; and to coordinate emergency response when major events occur.

The island is also divided into 14-parish committees and smaller community-based zonal communities, which coordinate disaster response at the parish and community level. A recent ODPEM review estimates our preparedness to deal with disasters at about $75 \%$; however, major deficiencies still exist in communications infrastructure and transportation capabilities. Only about $30 \%$ of the equipment necessary in the event of a major disaster is currently available.

\section{The future}

With advances in academics and emergency medical services, Jamaica is poised to move beyond a "developing" emergency care system. The UHWI has now established an academic department, led by residency-trained EM consultants involved in postgraduate training and research. There are 2 fully trained emergency physicians at the Kingston Regional Hospital and 3 at other public hospitals. 
Emergency medical services were initiated in the western section of the island in 1990, and private ambulance service is currently available in Kingston and the North Coast resort areas. When existing plans to extend government emergency medical services island-wide are achieved, Jamaica's emergency care will have moved into the developed phase.

Competing interests: None declared.

\section{References}

1. US Department of State, Bureau of Western Hemisphere Affairs, Feb 2005. Background note: Jamaica. Available: www .state.gov/r/pa/ei/bgn/2032.htm (accessed 2005 July 26).

2. Pan American Health Organization. Health in the Americas, vol 2. Jamaica: the Organization: 2002. p. $365-77$.

3. Statistical Institute of Jamaica. Jamaican statistics. Available: http://statinja.com/stats.html\#5 (accessed 2005 July 26).

4. Global Exchange. Programs in the Americas. Economics: Jamaica. Globalization, the IMF, and the future. Available: www .globalexchange.org/tours/jamaica.html/economy.html (accessed 2005 July 26).
5. Berk WA. Emergency medicine in the Third World: two years as director of the Kingston, Jamaica, Public Hospital Casualty Department. Ann Emerg Med 1989;18:567-72.

6. Dystra EH. International models for the practice of emergency care Am J Emerg Med 1997;15:208-9.

7. McDonald A, Duncan ND, Mitchell DIG, Fletcher PR. Trauma aetiology and cost in the accident and emergency unit at the University Hospital of the West Indies. West Indian Med J 1999;48:141-2.

8. McDonald AH, Duncan ND, Dawkins N., Mitchell DIG. Morbidity patterns of emergency room cases in Jamaica. West Indian Med J 2000;49:55

9. McDonald A, Ali J, Adam R, Mitchell DIG, Newnham M, Barnett A, et al. Potential role for the Advanced Trauma Life Support (ATLS $囚)$ Programme in improving trauma care in Jamaica. West Indian Med J 2003;51:45-8.

Correspondence to: Dr. Archibald McDonald, Department of Surgery, Radiology Anaesthesia and Intensive Care, University of the West Indies, Mona, Kingston 7, Jamaica; 876 927-1270, fax 876 970-4302, archibald.mcdonald@uwimona.edu.jm 